\title{
EDUCAÇÃO DO ANORMAL A PARTIR DOS TESTES DE INTELIGÊNCIA
}

\author{
Ricardo Antonio Gonçalves Teixeira ${ }^{1}$
}

\section{RESUMO}

A pesquisa busca compreender a presença dos testes de inteligência no campo da educação especial no Brasil. Para tanto, se vale de um estudo documental e bibliográfico a partir de fontes que remontam o contexto da educação no Brasil do início do século XX à década de 1970. Expõe o processo de construção do teste de Binet-Simon, bem como sua entrada ao Brasil no ano de 1906. Discute a aplicação do teste no campo educacional, mais especificamente na educação especial. Como resultado, apresenta a ausência de políticas públicas de atenção à pessoa com deficiência, a relação direta da educação com o campo da saúde pautada no diagnóstico e a caracterização do teste como determinante para o processo de exclusão e isolamento compulsório da pessoa com deficiência do contexto escolar e social.

Palavras-chave: Teste de Binet-Simon, Testes de inteligência, Educação especial, educação do anormal, pessoa com deficiência.

\section{EDUCACIÓN DEL ANORMAL A PARTIR DE LAS PRUEBAS DE INTELIGENCIA}

\footnotetext{
${ }^{1}$ Universidade Federal de Goiás (UFG), Goiânia/GO, Brasil.
} 


\section{RESUMEN}

La investigación busca comprender la presencia de las pruebas de inteligencia en el campo de la educación especial en Brasil. Así, se propone un estudio documental y bibliográfico, a partir de fuentes que remontan un contexto de la educación en Brasil, desde el inicio del siglo XX hasta la década de 1970. Expone el proceso de construcción del ensayo de Binet-Simon, así como su entrada a Brasil. Discute la aplicación de la prueba en la educación especial. Se presenta como resultado, la ausencia de políticas públicas de atención a la persona con discapacidad, relación directa de la educación con el campo de la salud pautada en el diagnóstico, caracterización de la prueba como determinante para el proceso de aislamiento obligatorio de la persona con discapacidad del contexto escolar y social.

alabras-clave: Prueba de Binet-Simon, Prueba de inteligencia, educación especial, educación de lo anormal, persona con discapacidad

\section{EDUCATION OF THE ABNORMAL FROM THE INTELLIGENCE TESTS}

\section{ABSTRACT}

The research aims to understand the presence of intelligence tests in the area of special education in Brazil.

Thus, it is characterized as a documentary and bibliographic study, from sources that seek a context of education in Brazil. The text states that the process of construction of the test of Binet-Simon, as well as its entrance to Brazil. Performs an analysis of the application of the special education area test. The results of the study expose the absence of public policies of attention to the person with disability, direct relation of education with the health area valued to the clinical diagnosis, as well as the characterization of the test as determinant for the process of exclusion and compulsory isolation of the person with in schools and society.

Keywords: Binet-Simon test, Test of intelligence, Special education, Education of the abnormal, Disabled person

\section{ÉDUCATION DE L'ANOMAL AUX ESSAIS D'INTELLIGENCE}

\section{RÉSUMÉ}

La recherche vise à comprendre la présence de tests d'intelligence dans le domaine de l'éducation spéciale au Brésil. Il présente une étude bibliographique, à partir de sources présentant un contexte d'éducation au Brésil, du début du XXe siècle au décennie de 1970. Le texte indique le processus de construction du test de Binet-Simon et son entrée au Brésil. Évalue l'application du test dans le domaine de l'éducation, plus spécifiquement dans l'éducation spéciale. La recherche révèle le manque de politique d'attention du public pour les personnes handicapées, la relation directe entre éducation et santé basée sur le diagnostic et la caractérisation du test comme facteur déterminant. le processus d'isolement obligatoire de la personne handicapée de l'école et le contexte social.

Mots-clés: Test de Binet-Simon, Tests d'intelligence, Éducation spéciale, Éducation de l'anomal, Personne handicapée 


\section{INTRODUÇÃO}

Este artigo parte de uma questão pouco estudada na área da educação especial: como se deu o uso dos testes de inteligência no campo educacional, especificamente para a pessoa com deficiência? Elegendo como objetivo elucidar tal questão no âmbito histórico, dentro de um contexto político, nos propomos a conduzir a pesquisa com base em um estudo documental e bibliográfico. As fontes utilizadas remontam o contexto da educação no Brasil no início do século XX à década de 1970, período em que se deu, com maior intensidade, a aplicação dos testes de avaliação do nível mental proposto por Binet e Simon e demais colaboradores/revisores e o reflexo no campo educacional desse instrumento, principalmente na condução das ações destinadas à pessoas com deficiência.

Em função do recorte temporal adotado, foram utilizadas diferentes terminologias acerca da pessoa com deficiência (ora denominada de anormal, oligofrênica - cretina, imbecil e idiota -, retardada, excepcional, demente, louca) e do campo de atenção da educação especial (pessoas com deficiência, abandonadas, delinquentes, epiléticas, portadoras de doenças infectocontagiosas).

O estudo, embora tente apresentar o cenário nacional, expõe algumas particularidades regionais como ponto de inflexão, avaliadas como necessárias a compreensão do contexto apresentado.

Os resultados do estudo remontam uma história importante a ser compreendida e questionada, principalmente pela característica excludente que o dito anormal educável foi tratado nas instituições especializadas em deficiência, pela natureza segregatória de sua institucionalização compulsória em clínicas de saúde mental e pela ausência do Estado na formulação de políticas de atenção e cuidado à pessoa com deficiência. 


\section{AVALIAÇÃo dO NÍVEL MENTAL A PARTIR DE TESTE PSICOLÓGICO}

Os testes psicológicos ganharam força a partir do início do século $\mathrm{XX}$ com o seu poder de mensuração de inteligência e de outros tipos de avaliações, cuja aplicação influenciou sobremaneira no contexto educacional de todo o mundo, não diferentemente no Brasil.

Embora os testes de inteligência tenham estado presentes em diferentes momentos e locais da história, foi a partir de procedimentos padronizadores de aplicação e interpretação, com uso em diferentes contextos sociais, que eles tomaram proporções de importância mundial. Esse processo de padronização partiu da publicação dos estudos dos franceses Alfred Binet e Théodore Simon a partir de escalas métricas com mensuração de níveis mentais de crianças e adolescentes em estudos realizados na Europa no início do século XX, que provocaram importantes mudanças no contexto das pesquisas em educação e psicologia.

Envolvidos em estudos sobre o diagnóstico do retardo mental ${ }^{2}$ e a educação de crianças anormais, Binet e seu colaborador Simon apresentam os resultados do trabalho no Congresso Internacional de Psicologia, em Roma, no ano de 1905 (ZAZZO, 2010). Esse estudo, em especial, se propunha verificar, por meio de diagnóstico, se as crianças possuíam ou não retardamento mental. Foi no ano de 1908 que os autores publicam uma escala métrica (termo anteriormente utilizado, porém não simpático para Binet) para mensurar a inteligência por meio de um teste denominado de Binet-Simon (BINET; SIMON, 1908).

A relevância do teste, percebida pela sociedade de pesquisadores, com uso amplo e irrestrito desse instrumento por diferentes profissionais em todo o mundo, destacando os da área de educação e da saúde. Estudos da época, a partir do uso do teste - com as contribuições do psicólogo alemão Stern, em

\footnotetext{
2 Ressalta-se que as nomenclaturas utilizadas no decorrer do texto referem-se aos termos da época/período, conforme impresso no documento.
} 
1912, que adequou a escala de Binet-Simon criando a escala do Quociente Intelectual (Q.I) ${ }^{3}$, e com revisão do psicólogo estadunidense Terman ${ }^{4}$, que igualou o número de testes para cada idade e os atualizou - de acordo com Fontoura (1964), mostraram forte correlação entre o Q.I e o nível de ocupação dos trabalhadores, fatores que encaminharam a postura determinística de seu uso/aplicação no contexto social.

A partir da composição da escala completa, o teste de Binet-Simon passou a classificar os indivíduos, em função de sua inteligência, medida pelo Q.I, em três grandes grupos: a) os normais; b) os supernormais; c) os infranormais. Sendo o Q.I a razão da Idade Mental (IM) pela Idade Cronológica (IC), ou seja: Q. I $=\frac{\mathrm{IM}}{\mathrm{IC}}$, o primeiro grupo, os normais, é composto por pessoas que obtiveram, no teste, resultados da IM igual ou muito próxima a IC próximo de 1. Para facilitar a sua visualização, pois nem sempre os resultados são inteiros, Terman propôs multiplicar o quociente por 100, assim, partindo da admissão do erro na constituição da escala estabeleceu-se considerar como normais os indivíduos com resultado (escore) no intervalo de 90 a 110.

O segundo grupo, os supernormais, é constituído daqueles cuja IM é maior que a IC, tendo como parâmetro escores maiores que 110. Desta feita, para o terceiro grupo, são considerados infranormais os sujeitos que atingirem escores inferiores a 90 pontos, ou seja, quando a IM é menor que a IC (FONTOURA, 1964).

Na escala de nível de Q.I, os três grandes grupos apresentam as seguintes classificações:

\footnotetext{
3 Escala de Q.I ou de nível mental que parametriza os escores do teste a partir de classificações. 4 A revisão feita por Terman, da Universidade de Stanford - EUA, foi apresentada no ano de 1916 (Muitos denominam a revisão por Stanford-Binet) e foi mundialmente reconhecida e aceita por pesquisadores e profissionais das áreas de educação e saúde (FONTOURA, 1964).
} 
Quadro 1: Quadro de classificação de Q.I

\begin{tabular}{|l|l|c|}
\multicolumn{1}{|c|}{ Q.I } & \multicolumn{1}{|c|}{ CLASSIFICAÇÃO } & $\begin{array}{c}\text { GRANDES } \\
\text { GRUPOS }\end{array}$ \\
\hline Mais de 140 & Gênio & $\begin{array}{c}\text { Os } \\
\text { supernormais }\end{array}$ \\
\hline Entre 120 e 140 & Inteligência muito superior & \\
\hline Entre 110 e 120 & Inteligência média superior & Os normais \\
\hline Entre 90 e 110 & Inteligência média ou normal & \\
\hline Entre 80 e 90 & Retardado mental & \\
\hline Entre 70 e 80 & Débil mental & Os infranormais \\
\hline Entre 50 e 70 & Cretino & \\
\hline Entre 25 e 50 & Imbecil & \\
\hline Abaixo de 25 & Idiota & \\
\hline
\end{tabular}

Fonte: Fontoura (1964, p. 13), adaptado.

Os sujeitos classificados nas três últimas escalas de Q.I - cretino, imbecil e idiota - são denominados de oligofrênicos, apresentados por Fontoura (1964) como defeituosos mentais. Para o autor, o cretino tem sua idade mental paralisada aos sete anos; o imbecil, aos cinco anos; enquanto que o idiota não desenvolve sua idade mental para além dos três anos de idade.

Faz-se importante compreender, na perspectiva de Binet, que a mensuração psicológica e pedagógica não é uma medida verdadeira, ou seja, não pode ser adotada no sentido matemático. Assim, por exemplo, em hipótese alguma se pode dizer que uma pessoa com Q.I 80 é duas vezes mais inteligente que outra pessoa com Q.I 40. De forma análoga, uma pessoa de Q.I 90 não é possuidora de 75\% da inteligência de outra com Q.I 120.

Os testes deram a Binet e Simon a capacidade de verificar numerosas semelhanças - até então não apontadas - entre normais e anormais, o que os faz concluir sobre a impossibilidade de apontar, apenas pelas descrições do teste, se uma criança é ou não normal tendo a sua idade desconhecida (BINET; SIMON, 1908).

Mas, afinal, a partir da escala de Binet-Simon, a pergunta que se fazia no âmbito de sua utilização nas escolas era: o que fazer com os estudantes classificados com Q.I abaixo de 80, os ditos infranormais? 
Na perspectiva de Binet, segundo Planchard (1975), a debilidade mental era considerada problema no contexto escolar nos níveis abaixo de 70, ou seja, para os oligofrênicos.

As escalas assumiam poder determinísticos na sociedade, ou seja, além da classificação dos indivíduos (seja com ou sem deficiência) apresentavam a sua capacidade mental e intelectual com indicação de profissões - denominados por Binet e Simon (1907) de orientação profissional - e tratamento para os mensurados como estado inferior de inteligência. Como exemplo, na perspectiva desses autores, na tradução de Santiago (2005), "Certamente, o idiota é para o hospício. Certamente o débil é para a escola. Resta o imbecil... A partir do momento em que não pode aprender nem a ler nem a escrever, seu lugar só pode ser no ateliê" (p. 78). Entende-se ateliê, na perspectiva apresentada, por espaço para o trabalho manual onde a inteligência não se faz necessária.

Ressalta-se que a educação da pessoa com deficiência era condicionada ao seu nível ou grau de excepcionalidade, segundo classificação nos testes de inteligência. Nesse processo de hierarquização, conforme distribuição na curva normal5 - parametrizada na variação de desvios-padrão - os resultados indicados como subnormalidade intelectual, os infranormais, variava entre deficientes mentais educáveis, treináveis e os graves e profundos (KIRK; GALLAGHER, 1979).

No âmbito da organização escolar, com base no Q.I, diferentes países assumiam posturas políticas distintas acerca dos infranormais educáveis, sendo a barreira dos escores de 70-80 no Q.I a principal forma de separação entre os sujeitos, de acordo com Magalhães (2018).

Faria de Vasconcellos (2015), educador português (1880-1939) ${ }^{6}$ fundador da Escola Nova de Bièrges-Les-Wavre (Bierges, Bélgica) e professor

\footnotetext{
5 Também conhecida como Curva de Gauss

${ }^{6}$ Assim como assim como John Dewey no Estados Unidos, Alfred Binet na França, Faria de Vasconcellos era um profundo defensor da Escola Nova.
} 
no Instituto Jean-Jacques Rousseau (Genebra, Suíça), sobre a educação daqueles classificados como infranormais, expõe em sua obra Uma Escola Nova na Bélgica que "Numa Escola nova aplica-se rigorosamente o princípio de que nenhuma criança com deficiência é aceite [sic] para bem de todos”, e complementa: "É essencial que os pais entendam que uma Escola nova não é um depósito nem o último recurso para os filhos quando o resto falhou" (p. 217).

$\mathrm{Na}$ Dinamarca, na década de 1930, havia políticas voltadas especificamente aos débeis mentais, aos cegos, aos surdos e aos epiléticos, além de uma comissão para assistência a crianças difíceis, subnormais e normais. Na Suécia, a organização geral das classes escolares obedecia a uma clara homogeneização de agrupamentos em conformidade com o nível intelectual das crianças. Assim, segundo Magalhães (2018), havia classes específicas para crianças com Q.I entre 40 e 70 e agrupamentos próprios para as com Q.I entre 70-80. Não diferente em Portugal e na Inglaterra, nesse período, os oligofrênicos recebiam tratamento diferenciado em instituições específicas, distantes das escolas de cunho regular. Por toda a Europa e em grande parte da América, as políticas eram favoráveis à adoção de pedagogias diferenciadas para os infranormais.

Em geral, pode-se dizer que a educação dos infranormais tidos como educáveis, ou seja, com Q.I mais próximo à classificação normal, e de pessoas com outros tipos de deficiência (visual, auditiva, física) era ofertada em caráter especial a partir de classes, turmas, salas de recursos e agrupamentos específicos, organizadas geralmente em instituições especializadas em deficiência.

Para as pessoas classificadas como oligofrênicas, o que imperava, enquanto prática após esse processo de classificação por meio dos testes psicológicos de inteligência, era o isolamento em instituições ligadas ao campo hospitalar como manicômios, sanatórios e hospício, geralmente em caráter compulsório (FONTOURA, 1964). 


\section{A PRESENÇA DO TESTE DE BINET-SIMON NO BRASIL E SEU REFLEXO NO CONTEXTO DA EDUCAÇÃO ESPECIAL}

As produções de Binet têm sua entrada reconhecida no Brasil a partir de 1906, por meio da criação do primeiro laboratório de psicologia pedagógica idealizada pelo referido autor e pela publicação da obra de Binet-Simon no Brasil, com tradução de Lourenço Filho (BINET; SIMON, 1929). Ressalta-se que essa entrada é justificada pela consideração de que "Binet estava à frente de importantes instituições de investigação científica da época, desempenhando aquilo que seria chamado hoje de 'pesquisa de ponta' da Europa do século XX" (ALMEIDA, 2010, p. 30).

Lourenço Filho, um importante reformista da educação no Brasil, na apresentação da referida obra, destaca a contribuição dos estudos em BinetSimon pelo seu valor histórico, a partir do "movimento actual de testes mentais" e pelo conhecimento de um processo de medida psicológica sem aparelhamento complicado (BINET; SIMON, 1929, p. 5).

Destaca-se o uso de teste em educandos "de infância anormal de inteligência”, em São Paulo, por Clemente Quaglio (1872-1948), com publicação do trabalho no ano de 1913 (QUAGLIO, 1913).

Não se pode deixar de anunciar os importantes laboratórios psicológicos, dentre os quais o Laboratório de Pedagogia Científica na Escola Normal Secundária de São Paulo, criado em 1914, que revela-se importante/revelevante para estudos experimentais, com instrumentos e aparelhos para fins exclusivamente pedagógicos ${ }^{7}$ (SILVEIRA, 1919).

Almeida (2010) apresenta a disposição de cinco tópicos sequenciais da notável presença de Binet no campo educacional no Brasil: (1) inserção

\footnotetext{
7 O referido laboratório em São Paulo, em 1925, com mudança de nome para Laboratório de Psicologia Experimental, da Escola Normal de São Paulo, passou a ser gerido por Lourenço filho, substituindo Sampaio Dória, que passou por um processo de revitalização (SGANDERLA; CARVALHO, 2008).
} 
institucional via laboratórios de psicologia pedagógica; (2) reformas nos currículos com a entrada da psicologia nas Escolas Normais; (3) produção intelectual sobre o aprofundamento da própria obra de Binet; (4) tradução de sua obra por Lourenço Filho, importante reformador brasileiro; (5) as bases do escolanovismo.

Em termos de contexto, o Brasil vivia, nos ides da década de 1920, profundas mudanças em âmbito social e educacional. Não havia no Brasil, até então, um sistema organizado de educação pública. Em um panorama de problemas conjunturais, no campo educacional não cabia suscitar políticas voltadas à escolarização do anormal, a partir da ideia de uma educação especial (nesse período eram considerados anormais os desviantes, dentre os quais enquadravam chamados deficientes, os abandonados e os delinquentes). Nesse sentido, para Ribeiro (2000), a educação especial não se caracterizava como um problema frente ao baixo nível de escolarização da população geral.

Um importante movimento que ocorria nesse período, mais fortemente na Europa e Estados Unidos, era o da Escola Nova, que tinha como essência a defesa por uma escola pública, universal e gratuita para todos. As ideias do filósofo e pedagogo estadunidense John Dewey (1859-1952), que pensava a educação como necessidade social, influenciaram importantes educadores brasileiros no contexto de reformas (PEREIRA et al., 2009; CAVALIERE, 2010).

Em meio a um processo de crise mundial, um movimento político no campo educacional se desenhava no Brasil, a partir das reformas em âmbito estaduais, dentre as quais se destacam: as reformas de Sampaio Dória, em São Paulo, em 1920; de Lourenço Filho, no Ceará, em 1923; de Anísio Teixeira, na Bahia, em 1925; Francisco Campos em Minas Gerais, em 1927; Fernando de Azevedo no Distrito Federal, em 1928; e novamente Lourenço Filho em São Paulo, também em 1930 (CAVALIERE, 2010).

O modelo de reforma implementado no final da década de 1920 em Minas Gerais, por Francisco Campos, foi importante nesse contexto. Instituída por um conjunto de decretos, as reformas foram iniciadas em 1927 com a 
apresentação do Regulamento do Ensino Primário (via Decreto n. 7.970A), seguidas, em 1928, do Regulamento do Ensino Normal (Decreto n. 5.122), do Programa do Ensino Primário (Decreto n. 8.094) e do Programa de Ensino Normal (Decreto n. 8.225). Em 1929 instituiu-se o Regulamento da Escola de Aperfeiçoamento (Decreto n. 8.987), com aprovação decretada em 1930 (Decreto n. 9.653).

É necessário ressaltar que a reforma mineira trouxe para a escola o modelo higienista da área da saúde, incluindo na escola profissionais como médicos, enfermeiros, dentistas, com o objetivo de construírem uma sociedade com base no princípio do corpo "limpo", "forte" e "sadio". Assim, como apresenta Jannuzzi (2004, p. 112), “A partir daquele momento o especialista passou a fazer parte do corpo administrativo da escola. A Inspetoria de Assistência Médica e Odontológica ficou juntamente com a Inspetoria Geral da Instituição Pública”, a escola, tendo a necessidade de cobrir as despesas assumidas, cria o Fundo Escolar e as Caixas Escolares. Para a autora, a educação do anormal (apresentado como deficiente), nesse ínterim, também apresentava o enfoque clínico/psicológico do modelo de escola regular vigente.

Com a constituição do Regulamento da Escola de Aperfeiçoamento, ano de 1929, de acordo com Januzzi (2004), Francisco Campos trouxe da Europa um grupo de psicólogos-professores, dentre os quais destaca-se Theódore Simon, colaborador de Binet na construção da escala de avaliação do nível mental e, mais adiante, a psicóloga russa Helena Antipoff, designada para assumir o Laboratório de Psicologia da Escola de Aperfeiçoamento de Belo Horizonte. Antipoff havia estudado no Laboratório de Binet-Simon e no Instituto Jean-Jacques Rousseau (FAZZI; OLIVEIRA; CIRINO, 2011).

O princípio higienizador e normalizador que a educação assume nesse período, indicam os caminhos da educação brasileira a partir da década de 1920 com as vertentes indicadas por Jannuzzi (2004) de médico pedagógica e psicopedagógica. Ainda que a presença desses profissionais da saúde na escola regular fosse marcante, ressalta-se que estes também passaram a se interessar 
"pela educação dos considerados anormais" (p. 97). Embora as ideias de normalidade e anormalidade estejam marcadas por um contexto de diferentes concepções e posicionamentos, há, de certo modo, consensos que conduzem às políticas e práticas no campo de gestão e atenção pedagógicas.

Em um artigo publicado pela Revista de Educação, de São Paulo (1927), revista que orientava as práticas escolares em todo estado, o docente da Faculdade de Direito de São Paulo, Sampaio Dória, responsável pela ação reformista em São Paulo, expõe a finalidade educativa da escola fundada no princípio da normalidade. Partindo da ideia de que "A todos os problemas pedagógicos, a finalidade educativa deve preceder" (REVISTA DE EDUCAÇÃO, 1927, p. 5), e da concepção de que a educação "é a interferência do homem na formação natural do homem" (p. 6), indica que a anormalidade não é um problema insolúvel. Para o autor considerando que todos os seres humanos desejam viver e que "a vida só triumpha com respeito às leis da natureza humana, a capacidade de adaptação às leis da vida é o que é natural, é o normal" (p. 11). Para ele, é, pois, considerado anormal, aqueles que, em função da sua incapacidade de atenção contínua, "lhes fallece intelligencia para conhecer as condições mais elementares da vida", como "o imbecil", "o demente" e "o louco", apresentando que "Sem a menor dúvida" que a "normalidade é a capacidade de adaptação [das pessoas] às leis da vida” (p. 11). Assim, a anormalidade é entendida, no contexto educacional, como elemento negativo: "Na educação, o primeiro dever é não anormalizar os educandos, isto é, não os prejudicar. $\mathrm{O}$ segundo dever é beneficiá-los, isto é normalizar e superiorizar, corrigindo as imperfeições, e ampliando as normalidades que os educandos tiveram” (p. 12). Como síntese, expõe que "É tudo normalizar as anomalias do corpo e do espirito, e superiorizar o homem normal ou normalizado. É um alto ideal não só legitimo, mas cabível em todos os tempos, superior a todas as raças, a todos os preconceitos e a todas as vicissitudes" (p. 15).

Para Norberto Souza Pinto, intelectual e professor especializado em ensino de pessoas "anormais" na Escola Sanatório de Campinas, em sua obra 
sobre a infância retardatária, a escola é um ambiente importante na identificação dos anormais, pois, é o local onde as anomalias são manifestadas. Ele parte da ideia de que é na infância - idade escolar - que o agravamento hereditário ou defeitos e atitudes adquiridas se manifestam (SOUZA PINTO, 1928). Os anormais, segundo apresenta, são seres miseráveis, os pobres de corpo e paupérrimos de espírito, "dignos de compaixão vegetando sobre a terra" (p. 64). Assim, no campo educacional, a criança anormal se caracteriza como um problema particular passível de um "tratamento bem delimitado" (p. 42). Defensor da segregação dos anormais, o autor justifica sua posição com o argumento de "não prejudicar os educandos normais" e nem a moralidade da instituição (p. 66). Norberto Souza Pinto era adepto ao uso dos testes psicológicos, para fins pedagógicos, assim como Binet-Simon. Porém, mais a frente passa a vincular os testes também ao campo médico como um recurso de diagnóstico (SOUZA PINTO, 1948).

Helena Antipoff, assim como o professor Norberto, era adepta ao movimento da Escola Nova e se posicionava também favorável ao ensino segregador dos chamados anormais que, com a presença massiva da equipe da saúde no contexto escolar, partia da concepção de que cabia à escola dar respostas aos problemas sociais. Partia também do uso do diagnóstico, avaliado por ela como um instrumento essencial nesse processo: “A educação das crianças débeis e anormais não pode ter êxito senão depois de estabelecido o respectivo diagnóstico" (p. 26). Com base em diagnósticos, resultantes dos testes de avaliação do nível mental de Binet-Simon, da qual fazia uso, classificava as crianças pelo grau de inteligência e instituía as classes homogêneas, princípio que propagou e perdurou nas décadas seguintes. Antipoff, diferenciava-se de Souza Pinto, por defender o ensino especial aos moldes do ensino regular, cuja distinção estaria no grau da abordagem médicopsicológica (ANTIPOFF, 1930).

O diagnóstico enquanto prática de organizações homogêneas de turma, por meio de classificação dos alunos em função da sua capacidade mental, 
proposta por Helena Antipoff, era a base adotada pela Secretaria de Educação do estado de Minas Gerais para o processo de individualização do ensino, conforme expõe o Boletim n. 14 da rede de educação mineira:

[...] o primeiro passo no sentido de individualizar o ensino é agrupar os alunos, tendo em vista o ritmo de desenvolvimento mental. $\mathrm{O}$ processo mais empregado hoje em dia é a seleção das crianças e sua concentração em classes homogêneas de valor forte, médio e fraco, organizadas em escalas de idades mentais. São numerosos os testes de inteligência global, de aplicação individual e coletiva, destinados às crianças em idade escolar. [...] O critério do Quociente Intelectual, como a experiência demonstrou, é superior ao simples critério da idade mental, para a formação de classes homogêneas [...] (BOLETIM N. 14 PUBLICAÇÃO DA SECRETARIA DE EDUCAÇÃO - MG, 1934, citado por ANTIPOFF, 1974, p. 56)

A partir do diagnóstico, as turmas eram organizadas conforme os níveis que os alunos alcançavam no teste. Àqueles classificados como anormais eram encaminhados, a depender do nível alcançado, para diferentes instituições ou serviços disponíveis. Em casos de deficiência intelectuais mais acentuadas, como os oligofrênicos, os testes eram aplicados em instituições manicomiais ou especializadas em doença mental.

Helena Antipoff, tendo como referência as experiências pedagógicas no referido laboratório em Belo Horizonte, fundou, em 1932, a sociedade Pestalozzi com reunião de toda a equipe de trabalho do laboratório e, em 1935, o Instituto Pestalozzi de Belo Horizonte, como órgão da Secretaria de Educação de Minas Gerais. Por meio de ações das entidades filantrópicas, modelo de educação especial de Antipoff foi ampliado em nível nacional (CAMPOS, 2003).

A década de 1930 é marcada no Brasil pelas profundas mudanças em termos políticos, econômicos, sociais e educacionais. Até 1930 vigorava, no Brasil, a chamada República Velha, marcada pelos fortes lastros do governo com os grandes proprietários de terras e pelas alternâncias de poder entre São Paulo e Minas Gerais (política café-com-leite). A República Velha foi interrompida 
com a tomada do poder de Getúlio Vargas, que permaneceu como governante por 15 anos consecutivos em seu primeiro período de gestão. O segundo período, compreendido entre 1951 e 1954, chamado de governo democrático, foi marcado por profundas crises políticas e pelo suicídio de Vargas que "saiu da vida para entrar na história".

O governo de Getúlio Vargas do primeiro período, denominado de Era Vargas, é compreendido em três momentos: o Provisório, no período de 1930 a 1934 - com foco na reorganização política do país, marcado pela centralização do poder e anulação dos poderes dos coronéis de terras e suas influências políticas; o Constitucional, de 1934 a 1937, marcado pela promulgação da Constituição de 1934, que limita o campo de atuação das forças armadas, amplia o direito de cidadania, gerando importante expectativa de mudança de vida face a ampliação do mercado de trabalho e do mercado consumidor; e o Estado Novo, de 1937 a 1945, marcado pela promulgação da Constituição de 1937, considerado como o período mais repressivo e ditatorial da Era Vargas, com cessão da independência dos três poderes, extinção dos partidos políticos, censura aos meios de comunicação, dentre outras ações.

No Governo Provisório, Vargas criou o Ministério da Educação e Saúde tendo como ministro Francisco Campos. Aos moldes das reformas conduzidas em Minas Gerais, Campos implementou, em 1931, a primeira reforma de caráter nacional, criando, dentre outros, o Conselho Nacional de Educação (Decreto n. 19.850/1931), organizou o ensino secundário (Decreto n. 1989o/1931), o ensino superior (Decreto n. 19.851/1931; Decreto n. 19.852/1931) e o ensino comercial (Decreto n. 20.158/1931). Francisco Campos não avançou na educação primária em virtude dos investimentos estarem voltados à educação profissional. Outro aspecto da reforma educacional é o retorno do ensino religioso nas escolas primárias, secundárias e normais no Brasil (MACHADO, 2014).

Frente ao descontentamento do ideário da Escola Nova, que defendia uma escola essencialmente pública, única, obrigatória, laica e gratuita, em 1932, um documento assinado por 26 intelectuais, denominados de Pioneiros da 
Educação Nova, apresentava um manifesto que circulou por todo o País para propor uma nova diretriz à política educacional do Brasil. Considerado como marco do processo de renovação educacional, o documento elaborado, por Fernando de Azevedo, Anísio Teixeira, Lourenço Filho, foi alvo de crítica de grupos sociais como a Igreja Católica que detinha, naquele momento histórico, parte expressiva das escolas da rede privada de ensino (SCHWARTZMAN; BOMENY; COSTA, 1984).

Em 1934, Gustavo Capanema assume o ministério da Educação e Saúde, dando continuidade à reorganização do ministério iniciada pelo seu antecessor, Washington Pires. Nesse período, frente aos embates travados entre o movimento escolanovista e o movimento católico (liderado por Alceu Amoroso Lima), Capanema não tomou posição explícita de apoio a nenhum dos movimentos, porém Schwartzman, Bomeny e Costa (1984) indicam que suas ações foram mais predominantes para o lado de Alceu.

No campo da saúde, Capanema iniciou suas ações de combate a doenças infectocontagiosas, das quais priorizou ações de combate a lepra. Para tanto, contou com o apoio da Federação das Sociedades de Assistência aos Lázaros e Defesa Contra a Lepra, com uma intensa campanha de natureza educativa em todo o território nacional. Com a aprovação do plano de reorganização do ministério, em janeiro de 1937, e criação do Departamento Nacional de Saúde e Assistência Médico-Social, deu-se início às ações no campo da saúde, expandidas para todo o território nacional. Com apoio da comunidade médica, foram iniciadas as construções de leprosários, dispensários e preventórios em todo o Brasil, a partir de uma política eugênica com a segregação compulsória dos doentes em benefício dos sãos (SILVA, 2013).

Tanto nos leprosários quanto nos preventórios, segundo Silva (2013), havia escolas e ações educativas. Cabe ressaltar que os preventórios se caracterizavam como instituições educacionais de educação formal e profissional ofertadas pelo estado para os filhos sãos de pais hansenianos, sendo desenvolvidas em atividades de lavoura, criação de animais, carpintaria, 
marcenaria, sapataria (para os homens) e cuidados do lar, costura e artesanatos (para as mulheres).

No ano de 1942, Capanema deu início às reformas na área educacional a partir das denominadas Leis Orgânicas, dentre as quais cabe mencionar a Lei Orgânica do Ensino Secundário (a ser ministrado em dois ciclos - o primeiro em um único curso, o ginasial; o segundo em dois cursos paralelos, o curso clássico e o científico) (Decreto n. 4.244/1942). Por influência da Segunda Guerra Mundial, a referida Lei instituiu a educação militar para os alunos do sexo masculino. Ressalta-se que a Lei Orgânica do Ensino Secundário permaneceu em vigor até 1961, com aprovação da Lei de Diretrizes e Bases da Educação Nacional (LDB).

Com a queda de Vargas, a presidência do Brasil é assumida por José Linhares, ficando no cargo por apenas três meses e cinco dias. Linhares elege como ministro da Educação e Saúde o médico Raul Leitão da Silva que, no curto período no cargo, consegue implementar, dentre outros: a Lei Orgânica do Ensino Primário (Decreto-lei n. 8.529/1946) - etapa até então desassistida pelo Governo Vargas; Lei Orgânica do Ensino Normal (Decreto-Lei n. 8.530/1946); Lei Orgânica do Ensino Agrícola (Decreto-Lei n. 9.613/1946).

No contexto de reformas apresentado, o campo da educação especial não recebeu atenção por parte dos governantes e reformistas. A forte e intensa relação do campo da saúde na educação, em um movimento político higienista e de combate às doenças infectocontagiosas, defendido e praticado nas décadas de 1910 e 1920, foi continuada, relação esta asseverada pela internação compulsória dos ditos anormais em instituições de tratamento como hospitais manicomiais, leprosários, casas de assistência ou apoio, abrigos e instituições de natureza privada especializada em deficiência - as denominadas instituições filantrópicas (MAZZOTTA, 2005).

Ainda que as informações expostas tenham surgido de uma ampliação do público de atenção à educação especial, é possível compreender que o foco no campo educacional se dirigiu, mais particularmente, às pessoas com deficiência 
e centrado no excepcional (com denominação atual de pessoa com deficiência intelectual).

Na perspectiva de Jannuzzi (1992), a defesa da educação dos excepcionais ou deficientes mentais representava a economia de recursos públicos, para evitar a segregação desses sujeitos em manicômios, asilos ou penitenciarias.

O modelo de educação especial proposto por Helena Antipoff, centrado em processos de classificação de sujeitos anormais, por meio de testes psicológicos para constituição de classes homogêneas, foi intensificado na década de 1950. O surgimento de instituições correlatas de modelo assistencialista, de natureza privada, como a Associação de Pais e Amigos dos Excepcionais (APAE), é expandido para todo o Brasil nas décadas de 1960 e 1970 e contemplado na primeira Lei de Diretrizes e Bases (LDB) do Brasil (Lei n. 4.024/1961) (MAZZOTTA, 2005; JANNUZZI, 2004).

Cabe reiterar que, embora haja registro de práticas no campo da educação referentes às pessoas com deficiências no Brasil desde o período imperial - meados do século XIX, com a construção de instituições para cegos e surdos, a discussão legal sobre a sua escolarização só se deu a partir do final da década de 1950 por meio das campanhas: de educação e reabilitação dos surdos (Decreto n. 42.728/1957), de educação e deficitários visuais (Decreto n. 44.236/1958) e de educação e reabilitação dos deficientes mentais (Decreto $\mathrm{n}$. 48.961/1960).

Tais campanhas visavam ampliar os centros de treinamento e reabilitação das pessoas com deficiência em todo território nacional. Grande parte das instituições que anunciavam ações educativas se possuíam clínicas e serviços particulares no campo médico-hospitalar, composto por profissionais da área da saúde (MAZZOTTA, 2005).

Como anunciado, somente em 1961, por meio da Lei de Diretrizes e Bases da Educação Nacional (LDB), via Lei n. 4.024, que a educação da pessoa 
com deficiência é contemplada em um documento legal em âmbito nacional. No Título X da LDB, Da Educação dos Excepcionais, dois artigos (88 e 89) abordam a questão sobre a educação de excepcionais. $\mathrm{O}$ art. 88 expõe o seu enquadramento, no que for possível, do deficiente "no sistema geral de educação, a fim de integrá-los à sociedade" e, o art. 89 reforça o investimento público às instituições privadas consideradas "eficientes" para atendimento dos excepcionais. A ênfase na deficiência intelectual, tratada no texto da LDB como para pessoas excepcionais, é destacada desde a década de 1930 pela crença de sua relação com o campo da saúde mental (JANNUZZI, 2004).

Não se trata, porém, de uma generalização do atendimento aos infranormais, pois, como apresentam Kirk e Gallagher (1979), mesmo na perspectiva do excepcional classificado como educável, o seu posicionamento ambiental dependia, ainda, do seu "grau de excepcionalidade". Observe, pela Figura 1, a presença de ambientes mais e menos restritivos que se encontravam em relação direta com o grau de excepcionalidade do educando, que varia de grave a moderado. A figura apresenta, também, uma ideia de proporcionalidade, em que o número de alunos é maior no extremo da avaliação de educandos com grau moderado, por conseguinte presentes em ambientes menos restritivos, e menor no outro extremo de avaliação grave, presentes em ambientes mais restritivos.

Figura 1: Ambientes especiais para crianças classificadas como excepcionais 


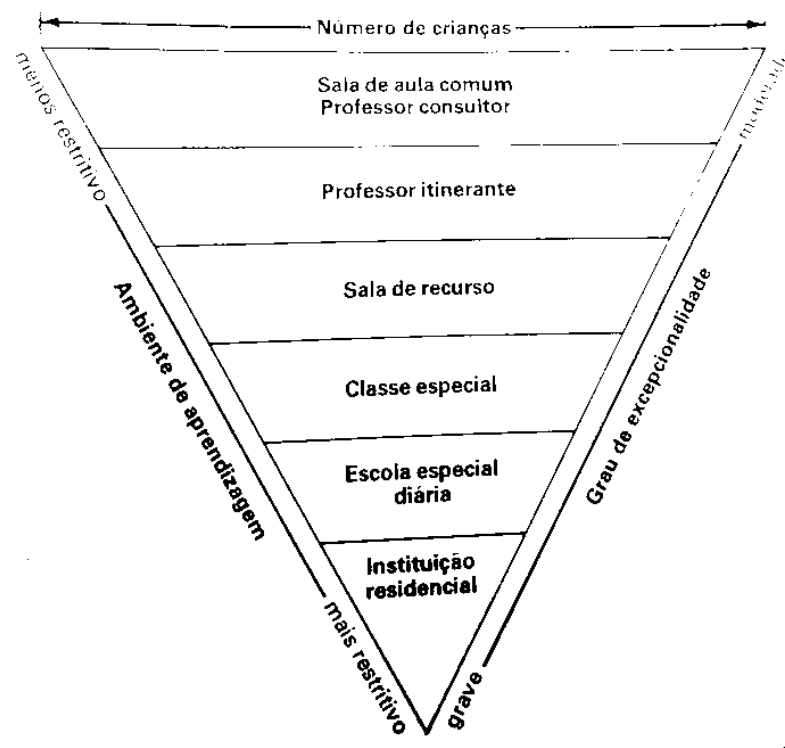

Fonte: Kirk e Gallagher (1979, p. 55).

É nesses termos de classificação dos sujeitos em função de seu nível mental que Fontoura (1964), em seu manual de testes, expõe a importância dessa avaliação na escola. Para o autor a avaliação consiste em diversos benefícios, tanto de custos e de tempo, quanto do que chama de energia nervosa:

[...] quantas vêzes fica a pobre professôra gastando sus energias, seu sistema nervoso, forçando por fazer certos alunos aprenderem cousas, acompanharem o desenvolvimento da turma! No entanto, tais alunos não podem seguir a turma porque seu Q.I não lhes permite! Então, não adianta a professôra "fazer fôrça", nem mesmo se desesperar! Seria a mesma cousa que exigir de um homem com um metro e sessenta de altura, que tenha 1,70 ! (p. 18).

Para o autor, não se pode incorrer no erro de insistir na tentativa de fazer uma criança anormal aprender determinados assuntos ou conteúdos, pois são constantemente reprovadas, muitas vezes castigadas e acabam por tomar lugar de outras crianças que não entram na escola por falta de vagas. Para Fontoura (1994, p. 18), 
Se o baixo Q.I dêsses meninos fosse verificado em tempo, a escola não incorreria no êrro de exigir de um aluno aquilo que êle não pode dar, porque está inteiramente acima de suas forças. Quantas vêzes o aluno tachado de "vadio", de "preguiçoso", de "sem capricho" e outros adjetivos deprimentes não é apenas um retardado ou um débil mental! Então, êle merece nossa compreensão, assistência, apoio, mas não teimemos em mantê-lo numa turma que não é sua!

Com a instituição da Lei n. 5.692/1971, que fixa diretrizes para o ensino de $1^{\mathrm{o}}$ e $2^{\mathrm{O}}$ graus em todo território brasileiro, além da deficiência intelectual, exclusivamente tratada na LDB/1961, o atendimento especial é estendido a alunos com deficiência física e altas habilidades no contexto de escolarização, a partir das seguintes prerrogativas:

Os alunos que apresentem deficiências físicas ou mentais, os que se encontrem em atraso considerável quanto à idade regular de matrícula e os superdotados deverão receber tratamento especial, de acôrdo com as normas fixadas pelos competentes Conselhos de Educação (art. $9^{\circ}$ ) (BRASIL, 1971).

A relação entre público e privado, no contexto da eficiência do serviço, fator presente nessa relação desde a década de 1930, também é destacada pelo documento por meio de incentivos do poder público:

Toda iniciativa privada considerada eficiente pelos conselhos estaduais de educação, e relativa à educação de excepcionais, receberá dos poderes públicos tratamento especial mediante bolsas de estudo, empréstimos e subvenções (art. 89).

Duas importantes instituições brasileiras especializadas em deficiência, mais especificamente na deficiência intelectual, Sociedade Pestalozzi e APAE, com o passar do tempo ampliaram seus serviços para todo o território nacional e ganharam força e espaço no âmbito político (MAZZOTTA, 2005).

Em 1960, com a instituição da Campanha Nacional de Educação e 
Reabilitação de Deficientes Mentais (CADEME), via Decreto n. 48.962/1960, foi criado um fundo especial, alimentado por dotações e contribuições da União, Estados e Municípios, na ordem pública, e de demais entidades paraestatais e de economia mista com previsão de donativos e fundos de contribuições de ordem financeira e patrimonial. Para Mazzotta (2005), as diretorias executivas da CADEME foram administradas, em sua grande maioria, e por longos períodos, pelos presidentes da APAE e Pestalozzi. Com recursos financeiros, e patrimoniais e força política, tais instituições passaram a ser consideradas essenciais e de utilidade pública, e tendo seus atendimentos considerados indispensáveis ao Estado.

Jannuzzi (2004), expõe que, o que eram práticas isoladas de atenção educacional especial, passaram a ser objetos oficiais, com tratamento legal, pautado no modelo clínico, ou seja, os serviços eram estruturados por entidades sociais, a partir de recursos públicos, com a ênfase na educação da pessoa com deficiência intelectual, com prevalência no diagnóstico clínico enquanto prática de classificação do sujeito para a prática do modelo de tratamento, visto que, naquele momento histórico, a deficiência assumia relação direta com doença.

Na perspectiva de Bueno (1993, p. 99),

\footnotetext{
A educação especial que nasce sobre a bandeira da ampliação de oportunidades educacionais aos que fogem da normalidade, na medida em que não desvela os determinantes sócio-econômicoculturais que subjazem às dificuldades de integração do aluno diferente, na escola e na sociedade, serve de instrumento para a legitimação de sua segregação.
}

É importante considerar que, embora as políticas implementadas após a Constituição Federal de 1988 (dentre as quais está a atual política de educação especial brasileira) garantam o direito de pessoas com deficiência de estudar em escolas comuns da rede regular de ensino, algumas instituições privadas especializadas em deficiência, ainda permanecem ofertando serviços educacionais similares ao contexto histórico apresentado, ou seja, em uma linha 
de tratamento clínico, valendo-se dos diagnósticos como eixo de classificação e modelo de serviço ofertado.

A percepção do anormal como um problema em si e desajuste social imperou, no Brasil, no modelo político-social, com reflexo no campo educacional. Na perspectiva de Jannuzzi (2004, p. 135), a estrutura que prevaleceu no contexto da educação especial no Brasil partia "das deficiências em si mesmas, do que diferia do normal, do que 'faltava', visando a proporcionar-lhes [sujeitos anormais], condições para suprir sua subsistência”, o que poderia ser entendido como normalização/preparação do sujeito anormal para as condições mínimas da vida social "no mundo dos normais".

\section{CONCLUSÃO}

A educação da pessoa "anormal” tem sido marcada, historicamente, por um contexto de segregação e exclusão. A relação da escola, tanto regular quanto especial, em seus diferentes contextos, com o campo da saúde foi marcante e intensa. O diagnóstico decorrente do teste de Q.I. era caracterizado como base para a organização dos alunos nas denominadas classes homogêneas, ou seja, o agrupamento dos alunos em salas de aula era feito de acordo com os níveis alcançados nos testes. Àqueles diagnosticados como oligofrênicos, eram considerados como não educáveis, assim não poderiam frequentar a escola e, em muitos casos, eram privados do convívio social.

Ressalta-se que o teste de Binet-Simon, a partir de uma escala de Inteligência, se constituiu como um instrumento de poder dos profissionais da saúde, como a classe médica que definia. Assim, por meio do diagnóstico, eram determinado quem podia ou não frequentar uma escola normal do ensino regular; participar ou não de espaços especiais de educação, mesmo limitados ao contexto da preparação do sujeito para viver nos mesmos espaços daqueles considerados normais; viver ou não na sociedade, sendo parte dos oligofrênicos 
submetidos ao isolamento pleno e total do convívio com as pessoas, espaços, meios e serviços.

Verifica-se que, desde o início do século XX até a década de 1970, pouco se evoluiu no contexto de políticas públicas de atenção à educação especial, sendo estas desconsideradas até a década de 1920 e terceirizada nos períodos seguintes para instituições privadas, a partir de recursos públicos.

Ressalta-se que, muito embora os testes de Q.I. tenham caído em desuso no campo da educação nas últimas décadas, o modelo de educação exclusiva para pessoas com deficiência, tendo como base o diagnóstico, ainda persiste. Mesmo na década de 1980, a partir do anúncio de uma nova constituinte (fruto de profundas discussões e luta de movimentos sociais), que aborda a educação como um direito de todos, a prática segregadora de instituições filantrópicas especializadas em deficiência não cessaram.

Há vertentes que ainda defendem o retorno da educação exclusiva e especializada-no modelo excludente, fundamentadas em questionamentos como: pessoas com deficiência, na escola comum, não atrasariam o desenvolvimento de outras crianças não deficientes? Por serem diferentes, não estariam sendo excluídas por esse modelo educacional? Uma escola de "iguais" não seria mais proveitosa para esses alunos, ainda mais por contar com profissionais especialistas?

Espera-se que o teor deste texto tenha proporcionado bases para reflexão acerca de tais questionamentos/posicionamentos.

\section{REFERÊNCIAS}

ALMEIDA, Danilo di Manno de. Binet no Brasil. In: ZAZZO, René (Org). Alfred Binet. Trad. Carolina Soccio Di Manno de Almeida. Coleção Educadores. Recife: Ed. Massangana, 2010. p. 29-42

ANTIPOFF, Helena. O ensino nas classes especiais. Exame Alpha e Match 
intellectual e escologia. Revista do Ensino, n. 50-52, out-dez, 1930.

ANTIPOFF, Ottília Braga. Educação do excepcional. Manual para professores. V. I. Guanabara: Edições Pestalozzi, 1974

BINET, Alfred; SIMON, Théodore. Le bilan de la psychologie en 1908. L’Année Psychologique, v. 15, n. 1, p. 5-12, 1908.

BINET, Alfred; SIMON, Théodore. Testes para medida do desenvolvimento da inteligência nas crianças. Tradução de Lourenço Filho. São Paulo: Editora Companhia Melhoramentos, 1929.

BINET, Alfred; SIMON, Theophile. Les enfants anormaux. Paris 5: Libraria Armand Colin, 1907.

BRASIL. Secretaria de Educação Especial. Política Nacional de Educação Especial na Perspectiva da Educação Inclusiva. Brasília, DF, jan. 2008a. [Documento elaborado pelo Grupo de Trabalho nomeado pela portaria $\mathrm{n}$. $555 / 2007$, prorrogada pela portaria n. 948/2007, entregue ao ministro da Educação em 7 de janeiro de 2008].

BUENO, José Geraldo Silveira. Educação especial brasileira: integração/segregação do aluno diferente. São Paulo: EDUC, 1993.

CAMPOS, Regina Helena de Freitas. Helena Antipoff: razão e sensibilidade na psicologia e na educação. Estud. av., São Paulo, v. 17, n. 49, p. 209231, Dec. 2003.

CAVALIERE, Ana Maria. Anísio Teixeira e a educação integral. Paidéia. maio-ago. 2010, Vol. 20, No. 46, 2010. P. 249-259.

FAZZI, Ernani Henrique; OLIVEIRA, Bernardo Jefferson de; CIRINO, Sérgio Dias. Notas sobre o Laboratório de Psicologia da Escola de Aperfeiçoamento de Belo Horizonte. Memorandum, 20. Belo Horizonte: UFMG; Ribeirão Preto: USP, 2011. p. 58-69.

FONTOURA, Afro do Amaral. A escola viva: manual de testes. 2. ed. Biblioteca Didatica Brasileira, vol. 10 ${ }^{\circ}$, série 1. Rio de Janeiro: Editora Aurora, 1964.

JANNUZZI, Gilberta. A luta pela educação do deficiente mental no Brasil. Campinas: Editores Associados, 1992.

JANNUZZI, Gilberta. A educação do deficiente no Brasil: dos primórdios ao início do século XXI. Campinas, SP: Autores Associados, 2004. 
KIRK, Samuel A; GALLAGHER, James J. Educação da criança excepcional. Tradução: Marília Zanella Sanvicentel. São Paulo: Fontes, 1979.

MACHADO, André Santana. Ecos e ocos da reforma Francisco Campos sobre o ensino de línguas no Brasil. História do Ensino de Línguas No Brasil. Ano 8, n. 8-1, 2014.

MAZZOTTA, Marcos J. S. Educação Especial no Brasil: História e políticas públicas. $5^{\mathrm{a}}$ ed., São Paulo: Cortez Editora, 2005.

PEREIRA, Eliana Alves; MARTINS, Jaqueline Riberio; ALVES, Vilmar dos Santos; DELGADO, Everaldo Inácio. A contribuição de John Dewey para a Educação. Revista Eletrônica de Educação. São Carlos, SP: UFSCar, v.3, no. 1, p. 154-161, mai. 2009.

PLANCHARD, Emille. A pedagogia contemporânea. 7. ed. Actualizada. Coimbra: Coimbra Editora, 1975.

QUAGLIO, Clemente. A solução do problema pedagógico-social da educação da infância anormal de inteligência no Brasil. São Paulo: Tip, Espinola e Comp., 1913.

REVISTA DE EDUCAÇÃO. Órgão da Directoria Geral da Instrucção Pública e da Sociedade de Educação, de São Paulo. V. 1, outubro, 1927, $115 \mathrm{p}$.

RIBEIRO, Maria Luísa Santos. História da educação brasileira: a organização escolar. Campinas, Autores associados, 2000.

SANTIAGO, Ana Lydia. A inibição intelectual na psicanálise. Rio de Janeiro: Jorge Zahar, 2005.

SCHWARTZMAN, Simon; BOMENY, Helena Maria Busquet; COSTA, Vanda Maria Ribeiro. Tempos de Capanema. São Paulo: FGV, 1984.

SILVA, Leicy Francisca da. Eternos órfãos da saúde - medicina, política e construção da lepra em Goiás (1830-1962). 2013. 358 f. Tese (Doutorado em História) - Universidade Federal de Goiás, Goiânia, 2013.

SILVEIRA, Carlos. História da instrução e da educação no Brasil. Revista da Escola Normal de São Carlos. São Paulo, ano 3, n.6. jun., 1919, p.13-32.

SGANDERLA, Ana Paola; CARVALHO, Diana Carvalho de. Lourenço Filho: um pioneiro da relação entre psicologia e educação no Brasil. Psicol. educ., São Paulo, n. 26, p. 173-190, jun. 2008. 
SOUZA PINTO, Norberto. A infância retardatária: ensaios de ortofrenia. 2. ed. São Paulo: Escolas Salesianas, 1928.

VASCONCELLOS, A. Faria de. Uma escola nova na Bélgica. Trad. Carlos Meireles-Coelho, Ana Cotovio, Lúcia Ferreira. - ${ }^{a}$ ed. - Aveiro: Universidade de Aveiro,2015. $320 \mathrm{p}$.

ZAZZO, René. Ensaio. In: ZAZZO, René (Org). Alfred Binet. Trad. Carolina Soccio Di Manno de Almeida. Coleção Educadores. Recife: Ed. Massangana, 2010. p.11-28.

RICARDO ANTONIO GONÇALVES TEIXEIRA é Professor Associado da Universidade Federal de Goiás, atuando nos cursos de graduação da Faculdade de Educação e no Programa de Pós-Graduação em Educação. Possuí Doutorado em Educação pela Faculdade de Educação da Universidade Federal de Goiás; pós-doutorado em Tecnologias de Investigação pelo Departamento de Educação da Universidade de Aveiro, Portugal (UA); pósdoutorado em Tecnologias Assistivas pela Faculdade de Engenharia da Universidade de Uberlândia - MG (UFU); pós-doutorado em Mídias Interativas pelo Programa Avançado de Culturas Contemporâneas da Universidade Federal do Rio de Janeiro - RJ (UFRJ); pós-doutorado em Educação Inclusiva e Saúde Coletiva pelo Programa de Pós-Graduação em Saúde Coletiva da Faculdade de Ciências Médicas da Universidade de Campinas - SP (Unicamp).

E-mail: professorricardoteixeira@gmail.com

(i) http://orcid.org/0000-0002-1603-2088

Recebido em: 31 de janeiro de 2019

Aprovado em: 28 de junho de 2019 